\title{
Book Review. Drugov, Yu.S. and Rodin, A.A., Ekologicheskaya analiticheskaya khimiya: Uchebnoe posobie (Environmental Analytical Chemistry: A Textbook), St. Petersburg: Anatoliya, 2002, 2nd ed., 464 pp.
}

\author{
DOI: $10.1134 / \mathrm{S} 1061934811040149$
}

In this textbook, theoretical bases of environmental analytical methods in chemistry are formulated in an accessible form using a great number of examples and their practical applications are surveyed. The methods are gas, high performance liquid, ion, and thin layer chromatography; capillary electrophoresis; atomic emission/absorption spectrometry; atomic fluorescence, UV, and IR spectrophotometry; luminescence; nuclear magnetic resonance, etc., spectrometry; mass spectrometry; electrochemical methods of analysis (voltammetry, potentiometry, coulometry, conductometry); hybrid methods (GC/MS, HPLC/MS, GC/IR-Fourier transform spectrometry, etc.); and test methods of chemical analysis.

Applied aspects of analysis are discussed in detail, from sample preparation and preconcentration of trace impurities to the identification of target components, their quantification, and metrological characterization of the results. Special attention is paid to the extraction of pollutants from matrices (air, water, soil), to the subsequent extraction of pollutants from a trap (sorption, extraction, cryofocusing, microwave heating, sorption on quartz fibers, supercritical fluid extraction, solid-phase microextraction, etc.), and to methods of identifying target components in complex mixtures of various nature and assessing toxicity either by means of traditional procedures or basic hybrid methods (GC/MS, GC/IR-Fourier transform, HPLC/MS, HPLC/GC, GC/TLC, GC/MS/IRFourier transform, GC/MS/AES, HPLC/MS/IRFourier transform, GC/MS/IR/AES, etc.).

Detailed information is given on analytical devices produced in the United States, European community, and Russia for quality assessment of air and water and determination of the degree of impurity in soils and vegetation.

The book provides insight into the possibilities of environmental analytical chemistry in controlling environmental pollution (including monitoring) and assessing the environmental status of different territo- ries. Analytical control is shown to be efficient for determining pollution in air (in the atmosphere, city air, the air of the working zone of industrial enterprises and office buildings, emissions from plants and factories), water (waste and natural waters, spring and tap water, rain and snow water, etc.), soil and bottom deposits (detection of heavy metals, organometallic compounds, poison gases and toxins in dumps, in places of chemical waste disposal, in the water area of seaports, etc.).

The textbook is intended for students, graduate students, and researchers working in chemistry and ecology. It can be useful for the personnel of research laboratories in industrial enterprises who uses chromatographic, spectrochemical, and electrochemical methods.

The textbook has proven quite useful for training students in chemistry (code 510500) specializing in analytical chemistry; physical chemistry; and environmental chemistry, chemical examination, and ecological safety at Samara State University. It is used in special courses of the theoretical fundamentals of chromatography; physical and chemical applications of gas-liquid chromatography; analytical gas and liquid chromatography; physical and chemical research methods; chromatography in medicine, biology, and ecology; chromatographic measurements; physical and chemical bases of environmental control; physical and chemical methods of analysis; analytical methods in environmental monitoring; and theoretical bases of analytical chemistry.

We would like to note that the performance characteristics of determinations in Chapter II must be supplemented by the requirements of GOST R ISO 57252002: Precision (accuracy and precision) of Methods and Results of Measurements.

\section{A. Onuchak, A. L. Lobachev, and I. A. Platonov}

